S. Aiston • L. J. Hampson • C. Arden •

P. B. Iynedjian $\cdot$ L. Agius

\title{
The role of protein kinase B/Akt in insulin-induced inactivation of phosphorylase in rat hepatocytes
}

Received: 24 May 2005 / Accepted: 28 July 2005 / Published online: 10 December 2005

(C) Springer-Verlag 2005

\begin{abstract}
Aims/hypothesis: An insulin signalling pathway leading from activation of protein kinase $\mathrm{B}$ (PKB, also known as Akt) to phosphorylation (inactivation) of glycogen synthase kinase-3 (GSK-3) and activation of glycogen synthase is well characterised. However, in hepatocytes, inactivation of GSK-3 is not the main mechanism by which insulin stimulates glycogen synthesis. We therefore tested whether activation of PKB causes inactivation of glycogen phosphorylase. Materials and methods: We used a conditionally active form of $\mathrm{PKB}$, produced using recombinant adenovirus, to test the role of acute PKB activation in the control of glycogen phosphorylase and glycogen synthesis in hepatocytes. Results: Conditional activation of PKB mimicked the inactivation of phosphorylase, the activation of glycogen synthase, and the stimulation of glycogen synthesis caused by insulin. In contrast, inhibition of GSK3 caused activation of glycogen synthase but did not mimic the stimulation of glycogen synthesis by insulin. PKB activation and GSK-3 inhibition had additive effects on the activation of glycogen synthase, indicating convergent mechanisms downstream of PKB involving inactivation of either phosphorylase or GSK-3. Glycogen synthesis correlated inversely with the activity of phosphorylase-a, irrespective of whether this was modulated by insulin, by PKB activation or by a selective phosphorylase ligand,
\end{abstract}

S. Aiston · L. J. Hampson · C. Arden · L. Agius $(\bowtie)$

School of Clinical Medical Sciences-Diabetes,

University of Newcastle upon Tyne,

NE2 4HH Newcastle upon Tyne, UK

e-mail: Loranne.Agius@ncl.ac.uk

Tel.: +44-191-2227033

Fax: +44-191-2220723

Present address:

S. Aiston

CV\&GI, AstraZeneca,

Macclesfield, SK10 4TG, UK

P. B. Iynedjian

Department of Cell Physiology and Metabolism,

University of Geneva School of Medicine,

1211 Geneva 4, Switzerland supporting an essential role for phosphorylase inactivation in the glycogenic action of insulin in hepatocytes. Conclusions/interpretation: In hepatocytes, the acute activation of PKB, but not the inhibition of GSK-3, mimics the stimulation of glycogen synthesis by insulin. This is explained by a pathway downstream of PKB leading to inactivation of phosphorylase, activation of glycogen synthase, and stimulation of glycogen synthesis, independent of the GSK-3 pathway.

Keywords Akt - Glycogen phosphorylase · Glycogen synthase - Glycogen synthase kinase-3 - Hepatocytes . Insulin · Protein kinase B

Abbreviations A2ER: A2myrAkt $\Delta 4$-129-oestrogen receptor - GSK-3: Glycogen synthase kinase-3 · HA: Haemagglutinin - MEM: Minimum essential medium . MER: Myristoylated Akt $\Delta 4$-129-oestrogen receptor . PDK1: Phosphoinositide-dependent protein kinase-1 . PI-3-kinase: Phosphoinositide-3-kinase .

PKB: Protein kinase B

\section{Introduction}

Control of the hepatic glycogen metabolism is a key component of the mechanism by which insulin maintains blood glucose homeostasis $[1,2]$. The stimulation of glycogen synthesis [3, 4], like insulin action in other cell types, is thought to occur downstream from the activation of the lipid kinase phosphoinositide-3 (PI-3)-kinase [5, 6]. The lipid products of PI-3-kinase activate a member of the AGC class of protein kinases termed phosphoinositide-dependent protein kinase 1 (PDK-1), which itself can phosphorylate and activate other protein kinases of the AGC family. Among the AGC kinase substrates of PDK-1, protein kinase B (PKB, also called Akt) has been widely implicated in mediating the metabolic actions of insulin [7]. PKB has two regulatory domains: an N-terminal PH domain, which comprises the lipid-binding region and is involved in the recruitment of the protein to the membrane, and a $\mathrm{C}$-terminal hydrophobic 
motif, which contains the phosphorylation site $\mathrm{S} 473$ and a docking site for PDK-1, which phosphorylates PKB on T308 [8].

The expression of constitutively active forms of PKB was reported to cause activation of glycogen synthase or stimulation of glycogen synthesis in L6 myotubes [9], Chinese hamster ovary (CHO) cells [10] and hepatocytes [11], and in 3T3 cells in some studies [12] but not in others [9]. Inhibition of the insulin-induced activation of glycogen synthase by dominant negative forms of PKB or by small interfering RNA-mediated silencing of the gene encoding PKB has also been reported in $3 \mathrm{~T} 3$ cells and L6 myotubes $[10,13,14]$.

One of the best characterised substrates of PKB is glycogen synthase kinase-3 (GSK-3), a negative regulator of glycogen synthase, which is inactivated by phosphorylation of a residue at the N-terminus [15]. Stimulation of glycogen synthesis and activation of glycogen synthase by overexpression of the gene encoding PKB or PKB activation are associated with phosphorylation of GSK-3 and have been attributed to inactivation of GSK-3 in nonhepatic cells [16, 17]. However, in differentiated hepatocytes, inactivation of GSK-3 is not the major mechanism by which insulin stimulates glycogen synthesis, inactivation of phosphorylase being key in this cell type [18]. In the present study we tested the hypothesis that stimulation of glycogen synthesis by insulin involves a signalling pathway leading to inactivation of phosphorylase. We tested the effects of acute stimulation of a conditionally active form of PKB $[19,20]$ on glycogen phosphorylase and glycogen metabolism in rat hepatocytes, and compared this with the effects of chemical inhibitors of GSK-3 and phosphorylase.

\section{Materials and methods}

\section{Materials}

SB-203580 and SB-216763 were from Tocris Cookson (Avonmouth, UK). CP-91149 [21] was a generous gift from Pfizer Global Research \& Development (Groton/New London Laboratories, CT, USA). [U- $\left.{ }^{14} \mathrm{C}\right]$ glucose, UDP $\left[6-{ }^{3} \mathrm{H}\right]$ glucose and $\left.{ }^{32} \mathrm{P}\right] \mathrm{ATP}$ were from Amersham Biosciences (Little Chalfont, UK). An adenoviral vector for a dominant negative form of PKB (T308A, S473A) was a kind gift from K. Walsh (Boston University School of Medicine, Boston, MA, USA) [22].

Hepatocyte monolayer culture and treatment with adenovirus

Hepatocytes were isolated by collagenase perfusion of livers from male Wistar rats (body weight 240-340 g, obtained from B \& K, Hull, UK) [23]. They were suspended in minimum essential medium (MEM) containing $7 \%(\mathrm{v} / \mathrm{v})$ newborn calf serum and were seeded in multi-well plates. Treatment with adenoviral vectors was started $2 \mathrm{~h}$ after cell plating. The adenoviral vectors for expression of a con- ditionally active form of PKB (MyrAkt $\Delta 4$-129-ER [MER] comprising a fusion protein of a PKB variant lacking the $\mathrm{PH}$ domain and containing a myristoylation sequence with the hormone binding domain of a mutant oestrogen receptor), and an inactive variant (A2myrAkt $\Delta 4$-129-ER [A2ER]) in which the myristoylation sequence is inactivated (C2A) have been described previously $[19,20]$. The adenoviral vector (DN-PKB) for a dominant negative mutant (T308A, S473A) form of PKB has been described elsewhere [22]. Adenoviral vectors were amplified in 293 cells and cell lysates for MER and A2ER vectors were titrated to equivalent stock titres based on the expression of the haemagglutinin (HA) tag in hepatocytes by immunoblotting. After cell attachment, hepatocytes were incubated for $2 \mathrm{~h}$ in serum-free medium containing various titres $(\mu \mathrm{l} / \mathrm{ml})$ of the adenoviral vectors. After $2 \mathrm{~h}$ incubation with the adenoviruses, the medium was replaced with serum-free MEM containing $10 \mathrm{nmol} / 1$ dexamethasone and the cells were cultured for $16-18 \mathrm{~h}$.

\section{Metabolic studies}

All incubations were performed after $16-18 \mathrm{~h}$ culture. Insulin was used at a final concentration of $10 \mathrm{nmol} / 1$. Hydroxytamoxifen [19,20], used to activate the conditional form of PKB (MER), and inhibitors of protein kinases and phosphorylase were dissolved in dimethylsulphoxide. Control incubations contained an equivalent solvent concentration $(0.1 \%[\mathrm{v} / \mathrm{v}])$. Parallel incubations were performed for determination of glycogen synthesis, glycogen synthase, phosphorylase-a activity and PKB phosphorylation. For determination of glycogen synthesis, hepatocytes were incubated for $3 \mathrm{~h}$ in MEM containing $\left[\mathrm{U}-{ }^{14} \mathrm{C}\right]$ glucose $(74 \mathrm{kBq} / \mathrm{ml})$ and the indicated glucose concentration. Radiolabelled glycogen was determined by ethanol precipitation [23] and is expressed as nmol of glucose incorporated in glycogen in $3 \mathrm{~h}$ per mg protein. Incubations without radiolabel were performed for determination of active glycogen synthase and phosphorylase-a.

\section{Enzyme activity determination}

Hepatocyte monolayers were snap-frozen in liquid nitrogen and stored at $-80^{\circ} \mathrm{C}$ until assay. Cells were extracted by sonication as described previously [18]. Glycogen synthase was determined in the whole homogenate from the incorporation of UDP $\left[6-{ }^{3} \mathrm{H}\right]$ glucose into glycogen in the absence or presence of $6.7 \mathrm{~mol} / \mathrm{l}$ glucose 6 -phosphate for determination of active and total glycogen synthase, respectively [24].

Phosphorylase-a was determined spectrometrically [25]. Active glycogen synthase and phosphorylase-a are expressed as $\mathrm{mU} / \mathrm{mg}$ cell protein, where $1 \mathrm{mU}$ represents the conversion of $1 \mathrm{nmol}$ of substrate/min. Activation of endogenous PKB- $\alpha$ by insulin was determined using a kit (\# 17-188) from Upstate Biotechnology (Lake Placid, NY, USA). Cells were extracted in a lysis buffer containing 
$50 \mathrm{mmol} / 1 \mathrm{Tris}-\mathrm{HCl}, \mathrm{pH} 7.5,1 \mathrm{mmol} / 1$ EDTA, $1 \mathrm{mmol} / 1$ EGTA, $0.5 \mathrm{mmol} / 1$ sodium vanadate, $0.1 \%$ (v/v) 2-mercaptoethanol, $1 \%$ Triton $\mathrm{X}-100,50 \mathrm{mmol} / \mathrm{l}$ sodium fluoride, $5 \mathrm{mmol} / 1$ sodium pyrophosphate, $10 \mathrm{mmol} / 1$ sodium $\beta$ glycerophosphate, $0.1 \mathrm{mmol} / \mathrm{l} \mathrm{PMSF}, 1 \mu \mathrm{g} / \mathrm{ml}$ of leupeptin, antipain and pepstatin and $1 \mu \mathrm{mol} / 1$ microcystin. Cell lysates $(500 \mu \mathrm{g}$ protein) were immunoprecipitated with an antibody to the PH domain and the kinase was assayed using RPRAATF as the substrate according to the manufacturer's instructions.

For determination of PKB activity in hepatocytes expressing MER or A2ER, cells were extracted in lysis buffer containing $0.1 \mathrm{~mol} / \mathrm{l}$ Tris- $\mathrm{HCl} \mathrm{pH} \mathrm{7.4,} 0.1 \mathrm{~mol} / \mathrm{l}$ potassium chloride, $25 \mathrm{mmol} / 1$ potassium fluoride, $1 \mathrm{mmol} / \mathrm{l}$ EDTA, $0.1 \%$ Triton $\mathrm{X}-100,1 \mathrm{mmol} / \mathrm{l}$ benzamidine, $1 \mathrm{mmol} / \mathrm{l} \mathrm{PMSF}$, $0.5 \mathrm{mmol} / \mathrm{l}$ sodium vanadate, $10 \mathrm{nmol} / \mathrm{l}$ okadaic acid and $10 \mu \mathrm{g} / \mathrm{ml}$ of leupeptin, antipain and pepstatin and immunoprecipitated (100 $\mu \mathrm{g}$ protein) with an antibody to the HA tag pre-bound to $\mathrm{A} / \mathrm{G}$ agarose. The immobilised immune complexes were recovered by centrifugation at $13,000 \times g, 4^{\circ} \mathrm{C}$ for $2 \mathrm{~min}$ and washed three times with lysis buffer. The pellet was incubated at $30^{\circ} \mathrm{C}$ for 30 min with $20 \mu \mathrm{l}$ of assay mixture containing $25 \mathrm{mmol} / \mathrm{l} \beta$-glycerophosphate, $\mathrm{pH} 7.4,100$ $\mathrm{mmol} / \mathrm{l}$ sodium chloride, $10 \mathrm{mmol} / \mathrm{l}$ magnesium chloride, $2.5 \mu \mathrm{mol} / \mathrm{l}$ protein kinase A inhibitor, $100 \mathrm{nmol} / \mathrm{l}$ okadaic acid, $100 \mu \mathrm{mol} / 1$ crosstide, $50 \mu \mathrm{mol} / 1\left[\gamma^{32} \mathrm{P}\right]$ ATP as in [3].

\section{Immunoblotting}

Cell lysates in gel loading buffer (7-20 $\mu$ g protein per well) were fractionated by SDS-PAGE $(10 \% \mathrm{w} / \mathrm{v})$ and protein was transferred to nitrocellulose membranes. Membranes were blocked for $2 \mathrm{~h}$ in 3\% BSA and incubated overnight with antibodies against PKB S473 and PKB T308 (Cell Signalling Technology, Beverly, MA, USA) followed by horseradish peroxidase-linked anti-IgG (Jackson Immunoresearch Laboratories, West Grove, PA, USA). Immunoreactive bands were detected using an ECL kit (Amersham Pharmacia) and quantified by densitometry.

Results are expressed as means \pm SEM for the number of experiments indicated. Statistical analysis was by the Student's $t$ test; $p$ values less than 0.05 were considered to be statistically significant.

\section{Results}

Time course of activation of endogenous PKB by insulin and of a conditionally active form of PKB (MER) by hydroxytamoxifen

To investigate whether insulin-induced inactivation of phosphorylase can be explained by PKB activation, hepatocytes were transduced with an adenoviral vector encoding a PKB variant termed MER (MyrAkt $\Delta 4-129-E R$ ), which can be activated acutely in cells by the synthetic oestrogen hydroxytamoxifen $[9,20]$. An adenovirus encoding a variant termed A2ER, which is not activated with hydroxytamoxifen, was used as a control [20]. Both MER and A2ER have a HA-tag to facilitate immunoblotting and immunoprecipitation. Figure 1a shows immunoreactivity to the HA-tag which was used to determine equivalent stock titres of MER and A2ER adenoviruses. Addition of hydroxytamoxifen (20
Fig. 1 Expression of MER and A2ER and ligand-induced phosphorylation of MER. a Immunoblot for the presence of HA-tag in hepatocytes treated with various adenoviral titres $(\mu \mathrm{l} / \mathrm{ml})$ of MER and A2ER and cultured for $16 \mathrm{~h}$. b Effects of incubation for $180 \mathrm{~min}$ with various concentrations of hydroxytamoxifen (HT) on phosphorylation of PKB S473 in cells pre-treated with $50 \mu \mathrm{l} / \mathrm{ml}$ MER adenovirus. c Time course of phosphorylation of $\mathrm{PKB}$ S473 and PKB T308 after addition of $200 \mathrm{nmol} / 1$ hydroxytamoxifen in cells pre-treated with $50 \mu \mathrm{l} / \mathrm{ml}$ MER or A2ER adenovirus. d Time course of phosphorylation of endogenous PKB S473 by insulin, showing also phosphorylation of expressed MER by $200 \mathrm{nmol} / 1$ hydroxytamoxifen after 180 min. Con control, $P-P K B$ phosphorylated PKB

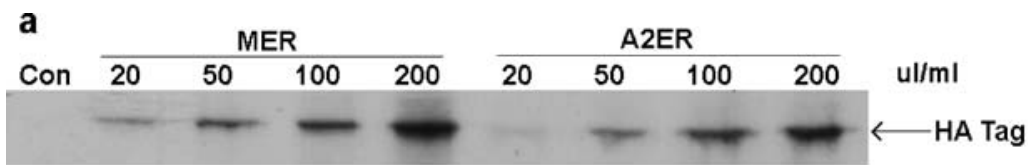

\section{b}
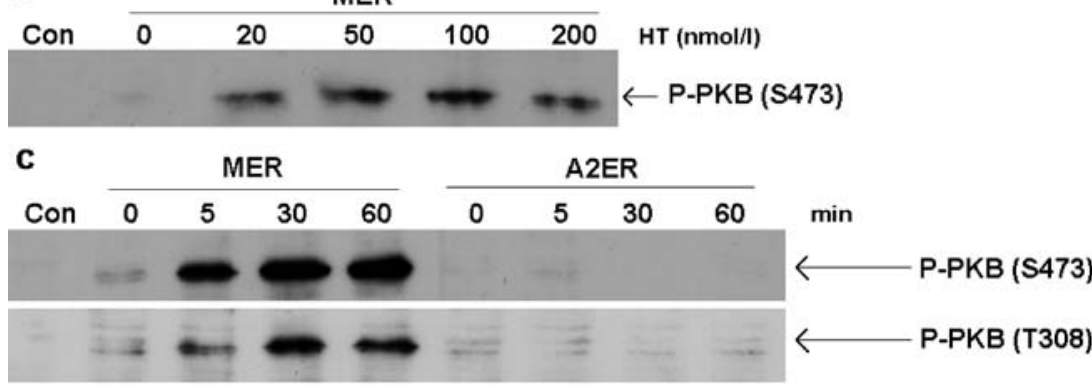

d

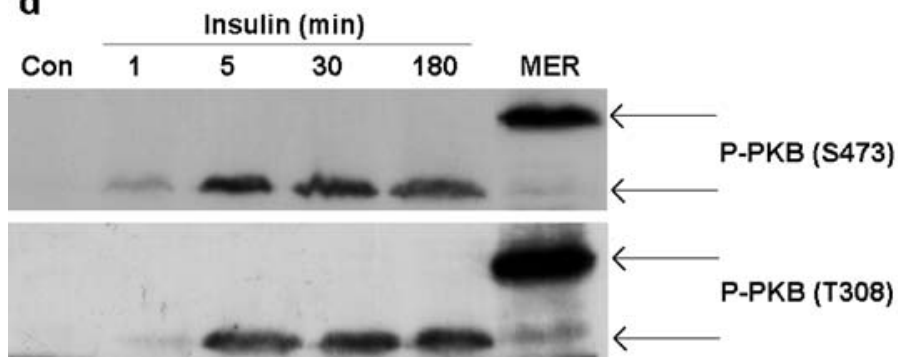


$200 \mathrm{nmol} / \mathrm{l})$ to hepatocytes expressing MER increased phosphorylation of PKB at S473 (90 kDa) corresponding to the expressed MER (Fig. 1b). The time course of the effect of hydroxytamoxifen (200 nmol/1) on S473 and T308 phosphorylation showed a rapid and sustained increase in cells expressing MER (Fig. 1c). Insulin caused a rapid increase in phosphorylation of S473 and T308 of endogenous PKB $(60 \mathrm{kDa})$ with maximal effect after 5 min (Fig. 1d). PKB activity, determined by immunoprecipitation, confirmed that hydroxytamoxifen activates PKB in cells expressing MER (Fig. 2a) but not in controls expressing A2ER (results not shown) and insulin caused rapid activation of endogenous enzyme with maximal effect at 5 min (Fig. 2b).

Activation of MER mimics insulin action on phosphorylase and glycogen synthesis

We examined the effects of stimulating PKB activity with different hydroxytamoxifen concentrations in hepatocytes
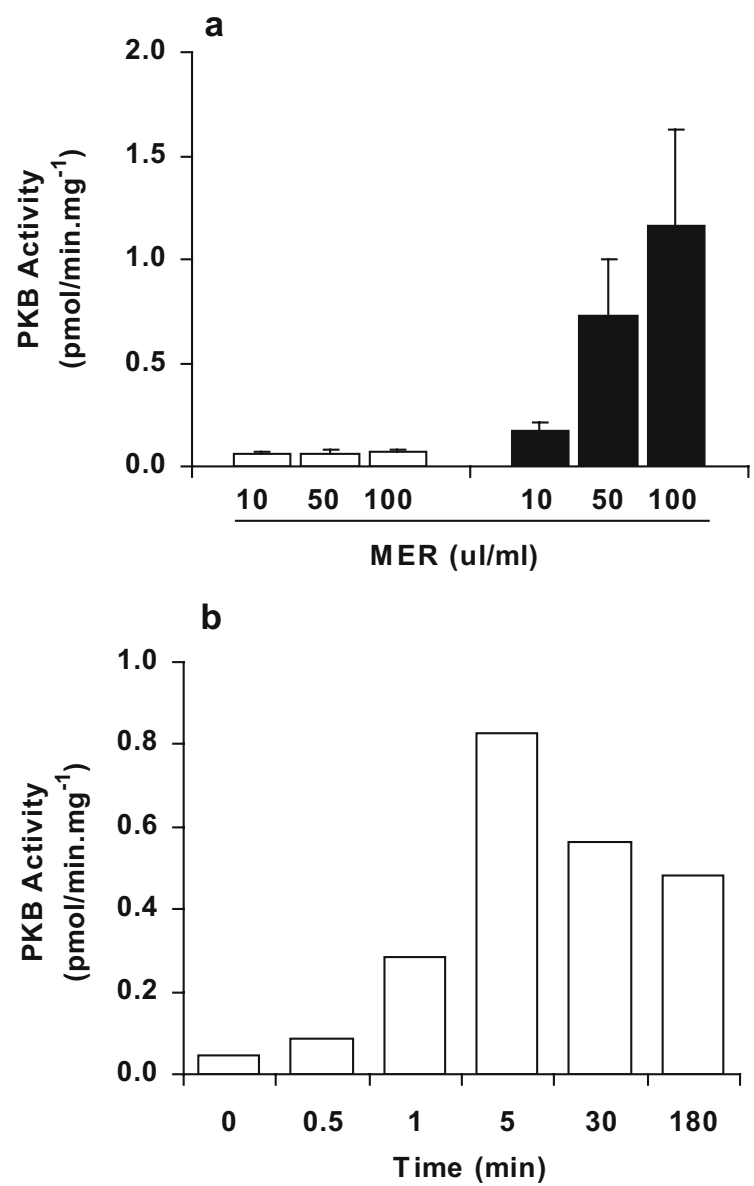

Fig. 2 Insulin-induced activation of PKB and ligand-induced activation of MER. a Hepatocytes treated with various titres of MER and incubated for $180 \mathrm{~min}$ without (open bars) or with (filled bars) $200 \mathrm{nmol} / 1$ hydroxytamoxifen. The data are the means \pm SEM of four experiments. b PKB activity in untreated hepatocytes incubated with $10 \mathrm{nmol} / 1$ insulin for the time intervals indicated. PKB activity was determined by an immunoprecipitate kinase assay as described in Materials and methods expressing MER or A2ER (Fig. 3). In the absence of hydroxytamoxifen (control), expression of MER or A2ER had no effect on either glycogen synthesis or on phosphorylase-a activity. Hydroxytamoxifen caused a concentration-dependent stimulation of glycogen synthesis and
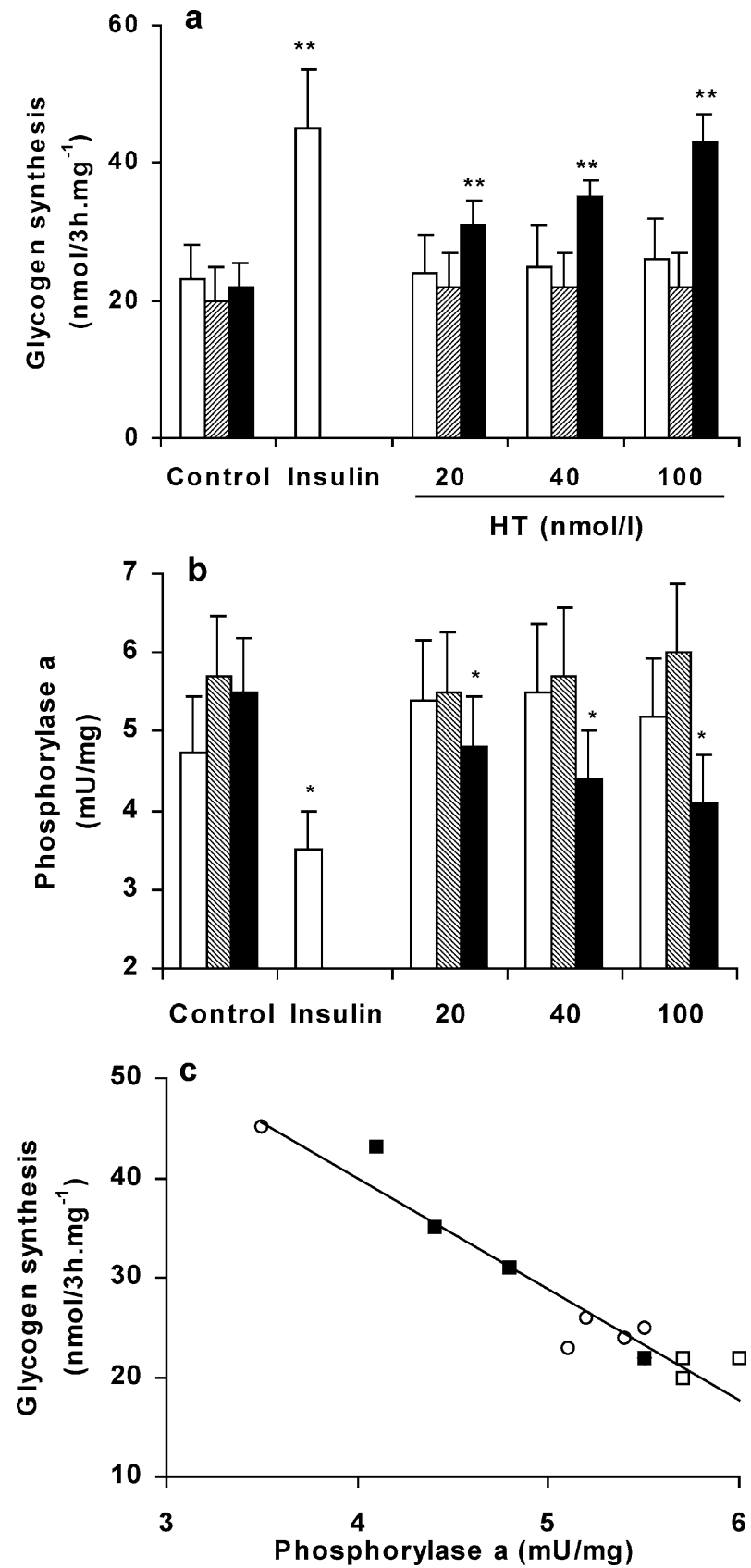

Fig. 3 Ligand-induced activation of MER mimics insulin action on glycogen synthesis (a) and depletion of phosphorylase-a (b). Hepatocytes were either untreated (open bars) or treated with $50 \mu \mathrm{l} / \mathrm{ml}$ A2ER (hatched bars) or MER (filled bars) adenovirus. After $16 \mathrm{~h}$ they were incubated for $3 \mathrm{~h}$ in MEM containing $15 \mathrm{mmol} / \mathrm{l}$ glucose without (control and insulin) or with hydroxytamoxifen (HT) at the concentrations indicated. Data are presented as the means \pm SEM of four experiments in both $\mathbf{a}$ and $\mathbf{b} .{ }^{*} p<0.05,{ }^{*} p<<0.01$ vs corresponding controls without HT. c Glycogen synthesis against phosphorylase-a activity. Open circles untreated, open squares A2ER, filled squares MER 
a
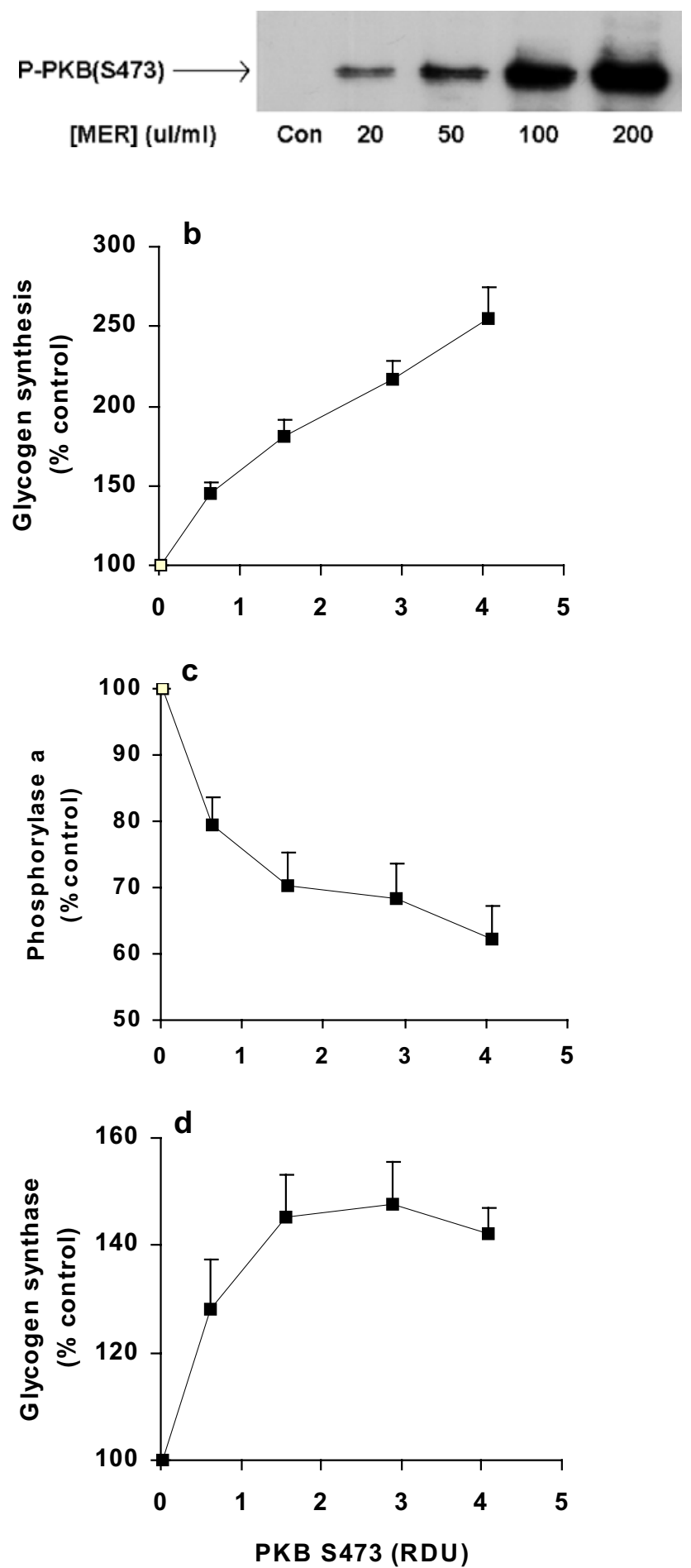

Fig. 4 Effects of MER expression on glycogen synthesis, phosphorylase-a and active glycogen synthase. Hepatocytes were either untreated (open symbols) or treated (closed symbols) with various titres of MER. After $16 \mathrm{~h}$ they were incubated for $3 \mathrm{~h}$ in MEM containing $15 \mathrm{mmol} / \mathrm{l}$ glucose and $200 \mathrm{nmol} / \mathrm{l}$ hydroxytamoxifen. Parallel incubations were performed for determination of immunoreactivity to P-PKB-S473 (a), glycogen synthesis (b), phosphorylase-a (c) and active glycogen synthase (d). A representative immunoblot is shown in $\mathbf{a}$. For b-d, results are expressed as percentage of controls and are plotted against the mean densitometry of P-PKB S473 immunoreactivity. Data are presented as the means \pm SEM of eight $(\mathbf{b}, \mathbf{c})$ or 4 (d) experiments. Con control, $P-P K B$ phosphorylated PKB depletion of phosphorylase-a in cells expressing MER, and mimicked insulin, but had no effect on cells with an equivalent expression of A2ER or on non-transduced cells (Fig. 3). In these experiments immunoreactivity to $\mathrm{S} 473$ and T308 was three-fold higher in cells expressing MER and incubated with hydroxytamoxifen relative to insulin-treated non-transduced cells.

We next examined the effect of graded expression of MER on glycogen synthesis and activities of phosphory-
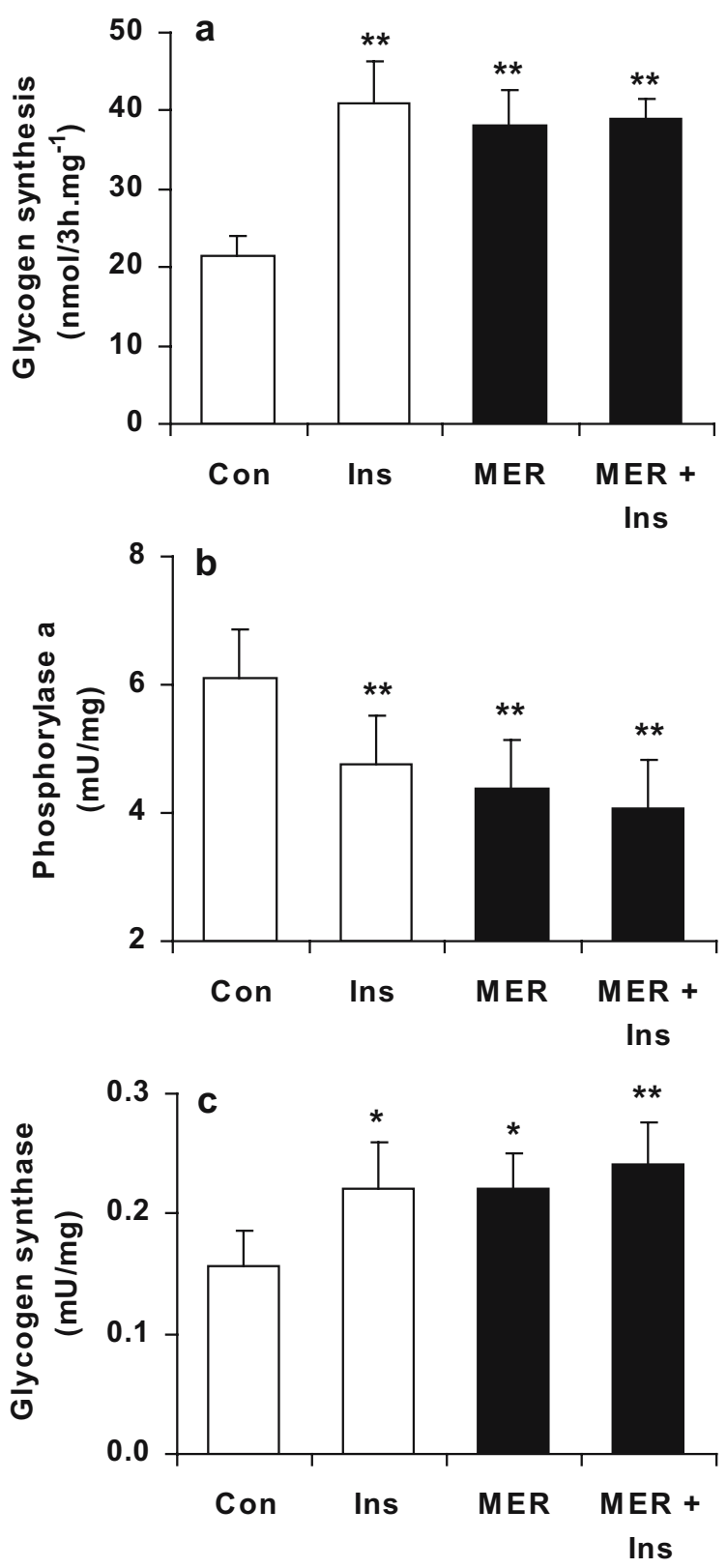

Fig. 5 The metabolic effects of insulin and activation of MER are not additive. Hepatocytes were either non-transduced (open bars) or treated (filled bars) with $50 \mu \mathrm{l} / \mathrm{ml}$ MER adenovirus. After $16 \mathrm{~h}$ they were incubated for $3 \mathrm{~h}$ in MEM containing $15 \mathrm{mmol} / 1$ glucose and $200 \mathrm{nmol} / 1$ hydroxytamoxifen without or with $10 \mathrm{nmol} / \mathrm{l}$ insulin and glycogen synthesis (a), phosphorylase-a (b) and active glycogen synthase (c) were determined. The data are presented as the means \pm SEM of eight $(\mathbf{a}, \mathbf{b})$ or four $(\mathbf{c})$ experiments. ${ }^{*} p<0.05,{ }^{*} p<0.005$ vs control. Con control, Ins insulin 
lase-a and glycogen synthase (Fig. 4). Increasing amounts of phosphorylated MER (S473) were associated with increments in the rate of glycogen synthesis and decrements in level of phosphorylase-a (Fig. 4). However, activation of glycogen synthase reached a plateau at intermediate levels of MER expression. At the highest titres of MER tested, shown in Fig. 4, the metabolic effects were greater $(p<0.05)$ than the effects of insulin for both
Fig. 6 SB-203580 inhibits PKB phosphorylation and partially counteracts the effects of insulin and MER. Hepatocytes were either non-transduced or treated with MER adenovirus $(50 \mu \mathrm{l} / \mathrm{ml})$. After $16 \mathrm{~h}$ culture they were incubated for 30 min with various SB-203580 concentrations (0 [open bars], 3

[hatched], 10 [crossed], or 30 [filled] $\mu \mathrm{mol} / \mathrm{l}$ ) and then incubated for $3 \mathrm{~h}$ in MEM containing $15 \mathrm{mmol} / 1$ glucose and $200 \mathrm{nmol} / \mathrm{l}$ hydroxytamoxifen without or with either insulin or $2.5 \mu \mathrm{mol} / 1 \mathrm{CP}-91149$. (a) Immunoblots to P-PKB-S473, and graphs to show effects of SB203580 on glycogen synthesis (b), phosphorylase-a (c) and glycogen synthesis vs phosphorylase-a (d) under the different conditions. Empty circles control, filled circles insulin, empty squares MER+ hydroxytamoxifen, filled squares, CP-91149. The graphs show the means \pm SEM of six experiments. $* p<0.05$ vs no SB-203570
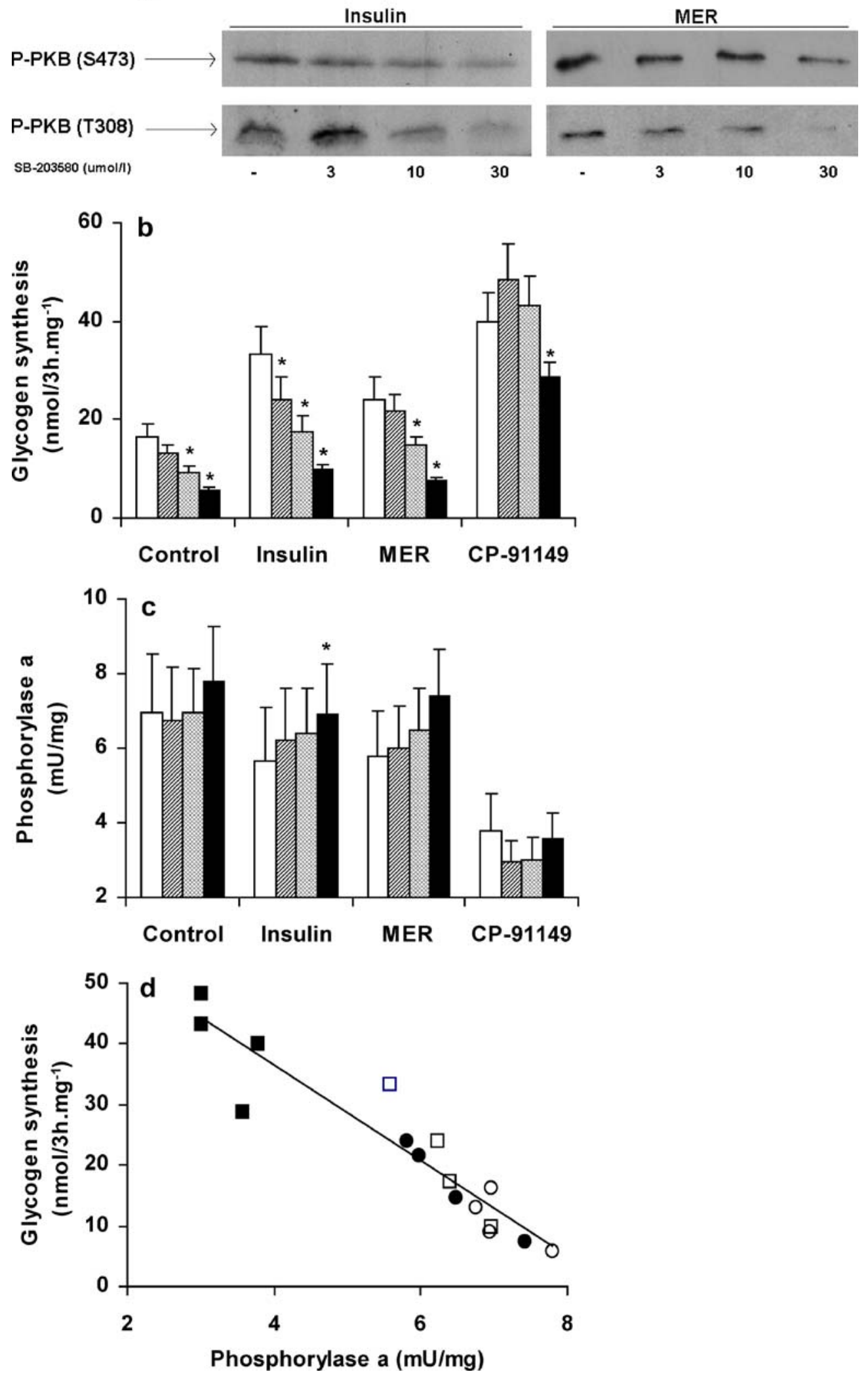
stimulation of glycogen synthesis (control 21 \pm 3 ; MER+ hydroxytamoxifen, $54 \pm 7$; insulin $41 \pm 5 \mathrm{nmol} / 3 \mathrm{~h} \cdot \mathrm{mg}^{-1}$ ) and inactivation of phosphorylase (control $6.1 \pm 0.7$; MER + hydroxytamoxifen $3.9 \pm 0.7$; insulin $4.8 \pm 0.8 \mathrm{mU} / \mathrm{mg}$ ). However, the activation of glycogen synthase by MER activation was similar to the activation caused by insulin (control $0.16 \pm 0.03$; MER+hydroxytamoxifen, $0.22 \pm 0.04$; insulin $0.22 \pm 0.04 \mathrm{mU} / \mathrm{mg}$ ). When the combined effects of insulin and intermediate levels of MER were tested, the stimulation of glycogen synthesis and activation of synthase was not additive relative to either treatment alone (Fig. 5).

Non-selective inhibition of PDK1 partially counteracts the metabolic actions of insulin and MER activation

We used an adenoviral vector (DN-PKB) for a dominant negative form of PKB [22] to test the role of PKB in insulin action. We confirmed a high level of expression from immunoreactivity to the HA-tag. With increasing expression of DN-PKB there was a decrease in both the basal and insulin-stimulated glycogen synthesis, with a persistent two-fold stimulation of glycogen synthesis by insulin at all levels of DN-PKB tested (results not shown). However, the stimulation of endogenous PKB by insulin was not affected by the DN-PKB, suggesting that this approach cannot be used to downregulate PKB in hepatocytes. The inability to counteract insulin-induced activation of PKB in hepatocytes by other dominant negative forms of PKB has been reported [26].

As an alternative approach to block the activation of endogenous PKB by insulin we tested the effects of SB203580 , which is a non-selective inhibitor of the upstream kinase, PDK-1 [27, 28]. Although SB-203580, is a potent inhibitor of p38-MAP-kinase [27], this kinase is not activated by insulin in hepatocytes. SB-203580 (3-30 $\mu \mathrm{mol} / \mathrm{l})$ suppressed the insulin-induced phosphorylation of endogenous PKB (T308 and S473) and the hydroxytamoxifen-induced phosphorylation of MER (Fig. 6a), which is compatible with inhibition of PDK-1 [27], and the effects of insulin and MER activation on glycogen synthesis and inactivation of phosphorylase-a (Fig. 6b,c). However, the stimulation of glycogen synthesis by the potent phosphorylase inhibitor CP-91149 [21], which causes dephosphorylation of phosphorylase-a and sequential activation of glycogen synthase [23], was less sensitive to inhibition by SB-203580 (Fig. 6b,c). In these experiments there was an inverse correlation between the rate of glycogen synthesis and the activity of phosphorylase-a (Fig. 6d).

Activation of PKB has an additive effect with inhibitors of GSK-3 on activation of glycogen synthase

Since inhibitors of GSK-3 cause a greater activation of glycogen synthase than insulin but a smaller stimulation of glycogen synthesis [18], we next tested the separate and combined effects of MER activation and inhibition of GSK-
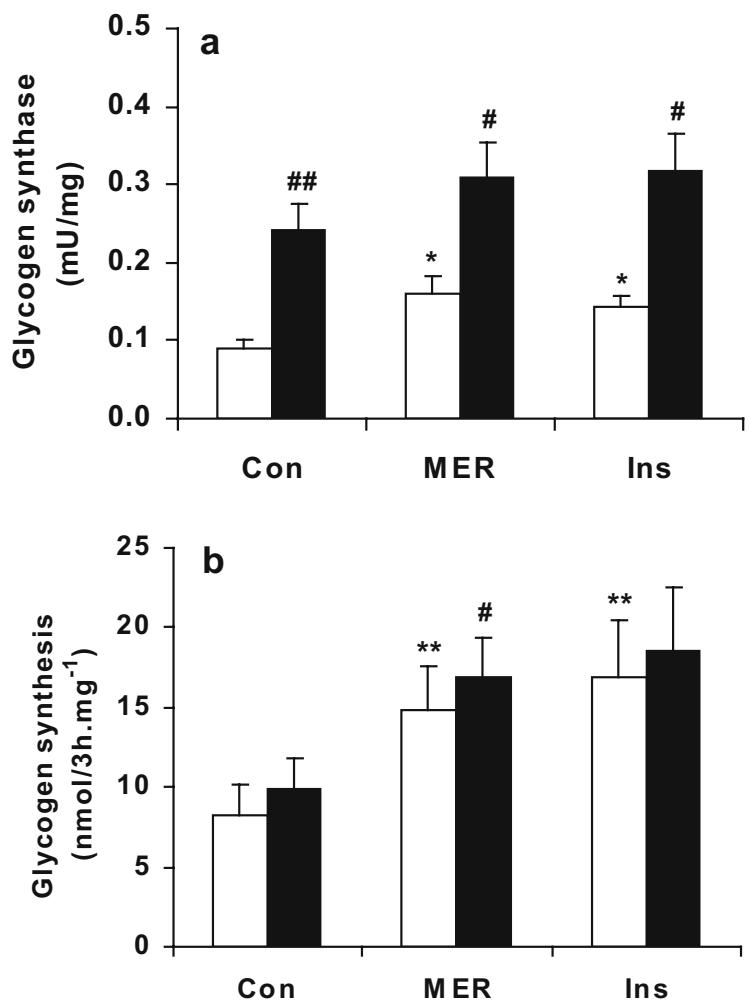

Fig. 7 Comparison of GSK-3 inhibition and ligand-induced MER activation. Hepatocytes without or with MER $(50 \mu \mathrm{l} / \mathrm{ml})$ expression were pre-incubated without (open bars) or with (filled bars) $2 \mu \mathrm{mol} / \mathrm{l}$ SB-216763 (GSK-3 inhibitor) for $30 \mathrm{~min}$ and then incubated for $3 \mathrm{~h}$ in MEM containing $15 \mathrm{mmol} / \mathrm{l}$ glucose and $200 \mathrm{nmol} / \mathrm{l}$ hydroxytamoxifen without or with $10 \mathrm{nmol} / 1$ insulin. The graphs show effects of SB-216763 on active glycogen synthase (a) and glycogen synthesis (b) under the different conditions. Data are presented as the means \pm SEM of six experiments. ${ }^{*} p<0.05, * * p<0.005$ for effect of insulin or MER; ${ }^{\#} p<0.05,{ }^{\#} p<0.005$ for effect of SB-216763

3 with a selective inhibitor [29]. Dose-response curves with the GSK-3 inhibitor (SB-216763) confirmed the maximum activation of glycogen synthase at $2 \mu \mathrm{mol} / \mathrm{l}$ and lack of effect on phosphorylase-a [18]. At $2 \mu \mathrm{mol} / 1$, the GSK-3 inhibitor caused a greater activation of glycogen synthase than insulin or MER activation ( $180 \%$ versus $60-80 \%$ stimulation, Fig. 7a); however, it caused a smaller stimulation of glycogen synthesis ( 20 versus $80-100 \%$, Fig. 7b). The effect of the GSK-3 inhibitor on glycogen synthase was additive with the effects of both MER activation and insulin (Fig. 7a), suggesting that $\mathrm{PKB}$ activation affects glycogen synthase by mechanisms additional to the inactivation of GSK-3. The greater stimulation of glycogen synthesis by MER compared with the GSK-3 inhibitor, despite the lower activation of glycogen synthase, can be explained by the requirement for inactivation of phosphorylase for stimulation of glycogen synthesis.

\section{Discussion}

The role of PKB activation in mediating the activation of glycogen synthase by insulin is supported by the expression of 
constitutively active forms of PKB (myr-Akt), which mimic the activation of glycogen synthase by insulin [9-11], and inhibition of activation of endogenous PKB isoforms by dominant negative mutants of PKB $[10,13]$ or by small interfering RNA-mediated gene silencing [10, 14]. This mechanism is generally attributed to PKB-mediated phosphorylation (inactivation) of GSK-3, a negative regulator of glycogen synthase [16]. However, in hepatocytes it is the inactivation of phosphorylase-a, and not the inactivation of GSK-3 that is a major component of the mechanism by which insulin stimulates glycogen synthesis [18]. We therefore tested the hypothesis that a signalling pathway downstream of PKB causes stimulation of glycogen synthesis by a mechanism involving inactivation of phosphorylase.

Using an adenoviral vector for a conditionally active form of PKB (MER) involving a fusion protein with a mutant oestrogen receptor which can be activated acutely by hydroxytamoxifen $[19,20]$ we demonstrate that activation of PKB causes a dose-dependent inactivation of phosphorylase (depletion of phosphorylase-a) and stimulation of glycogen synthesis and that it mimics the action of insulin on glycogen synthesis in hepatocytes. This contrasts with the inhibition of GSK-3, using a selective inhibitor, which despite causing a greater activation of glycogen synthase than insulin or PKB activation, does not mimic insulin action on glycogen synthesis [18]. The additive effects of the GSK-3 inhibitor and of PKB activation in causing the activation of glycogen synthase are consistent with a mechanism(s) downstream of PKB leading to activation of glycogen synthase independently of the inactivation of GSK-3. One such mechanism is dephosphorylation of phosphorylase-a, a negative regulator of glycogen synthase phosphatase [30]. In the current study, there was an inverse correlation between the rate of glycogen synthesis and the activity of phosphorylase-a in hepatocytes treated in three different ways: (1) with insulin; (2) with a phosphorylase inhibitor [21] that causes dephosphorylation of phosphorylase-a $[23,31]$; or (3) with various degrees of MER activation. Overall, these results strengthen the notion of a unique and critical role of depletion of phosphorylase-a in the glycogenic action of insulin in hepatocytes [18].

The present results together indicate that: (1) activation of glycogen synthase downstream of PKB is the combined effect of two distinct mechanisms involving dephosphorylation of phosphorylase-a and an independent mechanism most likely the result of phosphorylation of GSK-3; (2) inactivation of GSK-3 alone does not mimic insulin stimulation of glycogen synthesis; (3) inactivation of phosphorylase mimics insulin stimulation of glycogen synthesis; (4) activation of PKB alone mimics insulin-induced inactivation of phosphorylase, activation of glycogen synthase and stimulation of glycogen synthesis.

The insulin-like effects of PKB (MER) activation in causing the inactivation of phosphorylase and the stimulation of glycogen synthesis, support a major role for PKB activation in mediating the glycogenic effects of insulin. Whether this role is preferentially assumed by one of the specific isoenzymes $\mathrm{PKB} \alpha, \mathrm{PKB} \beta$, or $\mathrm{PKB} \gamma$ is currently unknown. Studies on gene knock-out mice or on cell lines derived from these mice, suggest a specific role for $\mathrm{PKB} \beta$ in the control of blood glucose homeostasis and the stimulation of glucose transport $[32,33]$ and this is supported by the autosomal dominant inheritance of extreme insulin resistance and type 2 diabetes in human subjects with a mutation in the gene for $\mathrm{PKB} \beta$ [34]. In hepatocytes, insulin causes activation of PKB isoforms $\alpha$ and $\beta$ with the former isoform accounting for a four-fold higher activation relative to the $\beta$ isoform [35]. Although we confirmed that inactivation of phosphorylase-a and stimulation of glycogen synthesis by expression of MER correlated with the immunoreactivity to S473 (and T308) in experiments with various titres of MER recombinant adenovirus or with various levels of hydroxytamoxifen, nonetheless the immunoreactivity to S473 in cells overexpressing MER was greater than in cells activated by insulin. It is conceivable that endogenous PKB isoenzymes activated by insulin might phosphorylate downstream targets more efficiently than artificially expressed MER, perhaps because of preferential interaction with particular substrates and/or distinct intracellular compartmentalisation.

The present finding that PKB activation causes inactivation of phosphorylase provides an explanation for the finding that expression of a constitutively active PKB variant in mouse liver in vivo induces marked hypoglycaemia in both the fasted and fed states [36]. Phosphorylase-a catalyses the flux-generating step of glycogenolysis and thereby has a key role in mobilisation of hepatic glycogen during fasting. It is also a potent allosteric inhibitor of glycogen synthase phosphatase in association with the glycogen targeting protein GL [30]. Accordingly, depletion of phosphorylase-a by dephosphorylation relieves the inhibition of glycogen synthase phosphatase, resulting in the activation of glycogen synthase and the stimulation of glycogen synthesis [30]. PKB-mediated inactivation of hepatic phosphorylase is thus predicted to lower blood glucose in both fed and fasted states. The mechanisms by which PKB activation causes inactivation of phosphorylase remain to be determined.

Acknowledgements We thank Diabetes UK for project grant and equipment grant support. We are grateful to K. Walsh for the adenovirus construct for the dominant negative Akt mutant and to J. Treadway for the CP-91149. The authors are not aware of any conflict of interest.

\section{References}

1. Michael MD, Kulkarni RN, Postic C et al (2000) Loss of insulin signaling in hepatocytes leads to severe insulin resistance and progressive hepatic dysfunction. Mol Cell 6:87-97

2. Edgerton DS, Cardin S, Emshwiller M et al (2001) Small increases in insulin inhibit hepatic glucose production solely caused by an effect on glycogen metabolism. Diabetes 50:1872-1882

3. Peak M, Rochford JJ, Borthwick AC, Yeaman SJ, Agius L (1998) Signalling pathways involved in the stimulation of glycogen synthesis by insulin in rat hepatocytes. Diabetologia 41: $16-25$

4. Lavoi L, Band CJ, Kong M, Bergeron JJ, Posner BI (1999) Regulation of glycogen synthase in rat hepatocytes. Evidence for multiple signaling pathways. J Biol Chem 274:28279-28285 
5. Shepherd PJ, Withers DJ, Siddle K (1998) Phosphoinositide 3kinase: the key switch mechanism in insulin signalling. Biochem $\mathrm{J}$ 333:471-490

6. Cantley LC (2002) The phosphoinositide 3-kinase pathway. Science 296:1655-1657

7. Vanhaesebroeck B, Alessi DR (2000) The PI3K-PDK1 connection: more than just a road to PKB. Biochem J 346:561-576

8. Scheid MP, Woodgett JR (2003) Unravelling the activation mechanisms of protein kinase B/Akt. FEBS Lett 546:108-112

9. Ueki K, Yamamoto-Hond K, Kaburagi Y et al (1998) Potential role of protein kinase B in insulin-induced glucose transport, glycogen synthesis, and protein synthesis. J Biol Chem 273:53155322

10. Katome T, Obata T, Matsushima R et al (2003) Use of RNA interference-mediated gene silencing and adenoviral overexpression to elucidate the roles of AKT/protein kinase B isoforms in insulin actions. J Biol Chem 278:28312-28323

11. Sakoda H, Gotoh Y, Katagiri H et al (2003) Differing roles of Akt and serum- and glucocorticoid-regulated kinase in glucose metabolism, DNA synthesis, and oncogenic activity. J Biol Chem 278:25802-25807

12. Kohn AD, Summers SA, Birnbaum MJ, Roth RA (1996) Expression of a constitutively active Akt Ser/Thr kinase in 3T3-L1 adipocytes stimulates glucose uptake and glucose transporter 4 translocation. J Biol Chem 271:31372-31378

13. Takata M, Ogawa W, Kitamura T et al (1999) Requirement for Akt (protein kinase B) in insulin-induced activation of glycogen synthase and phosphorylation of 4E-BP1 (PHAS-1). J Biol Chem 274:20611-20618

14. Jiang ZY, Zhou QL, Coleman KA, Chouinard M, Boese Q, Czech MP (2003) Insulin signaling through Akt/protein kinase $\mathrm{B}$ analyzed by small interfering RNA-mediated gene silencing. Proc Natl Acad Sci USA 100:7569-7574

15. Cross DA, Alessi DR, Cohen P, Andjelkovich M, Hemmings BA (1995) Inhibition of glycogen synthase kinase-3 by insulin mediated by protein kinase B. Nature 378:785-789

16. Frame S, Cohen P (2001) GSK3 takes centre stage more than 20 years after its discovery. Biochem J 35:1-16

17. van Weeren PC, de Bruyn KM, de Vries-Smits AM, van Lint J, Burgering BM (1998) Essential role for protein kinase B (PKB) in insulin-induced glycogen synthase kinase 3 inactivation. J Biol Chem 273:13150-13156

18. Aiston S, Coghlan MP, Agius L (2003) Inactivation of phosphorylase is a major component of the mechanism by which insulin stimulates hepatic glycogen synthesis. Eur J Biochem 270: 2773-2781

19. Kohn AD, Barthel A, Kovacina KS et al (1998) Construction and characterization of a conditionally active version of the serine/ threonine kinase Akt. J Biol Chem 273:11937-11943

20. Fleischmann M, Iynedjian PB (2000) Regulation of sterol regulatory-element binding protein 1 gene expression in liver: role of insulin and protein kinase B/cAkt. Biochem J 349:13-17

21. Martin WH, Hoover DJ, Armento SJ et al (1998) Discovery of a human glycogen phosphorylase inhibitor that lowers blood glucose in vivo. Proc Natl Acad Sci USA 95:1776-1781
22. Fujio Y, Walsh K (1999) Akt mediates cytoprotection of endothelial cells by vascular endothelial growth factor in an anchorage-dependent manner J Biol Chem 274:16349-16354

23. Aiston S, Hampson L, Gomez-Foix AM, Guinovart JJ, Agius L (2001) Hepatic glycogen synthesis is highly sensitive to phosphorylase activity: evidence from metabolic control analysis. J Biol Chem 276:23858-23866

24. Thomas JA, Schlender KK, Larner J (1968) A rapid filter paper assay for UDP-glucose-glycogen glucosyltransferase, including an improved biosynthesis of UDP ${ }^{14} \mathrm{C}$-glucose. Anal Biochem 25:486-499

25. Aiston S, Agius L (1999) Leptin enhances glycogen storage in hepatocytes by inhibition of phosphorylase and exerts an additive effect with insulin. Diabetes 48:15-20

26. Ribaux PG, Iynedjian PB (2003) Analysis of the role of protein kinase $\mathrm{B}(\mathrm{cAKT})$ in insulin-dependent induction of glucokinase and sterol regulatory element-binding protein 1 (SREBP1) mRNAs in hepatocytes. Biochem J 376:697-705

27. Lali FV, Hunt AE, Turner SJ, Foxwell BM (2000) The pyridinyl imidazole inhibitor SB203580 blocks phosphoinositide-dependent protein kinase activity, protein kinase B phosphorylation, and retinoblastoma hyperphosphorylation in interleukin-2-stimulated $\mathrm{T}$ cells independently of p38 mitogen-activated protein kinase. J Biol Chem 275:7395-7402

28. Godl K, Wissing J, Kurtenbach A et al (2003) An efficient proteomics method to identify the cellular targets of protein kinase inhibitors. Proc Natl Acad Sci USA 100:15434-15439

29. Coghlan MP, Culbert AA, Cross DA et al (2000) Selective small molecule inhibitors of glycogen synthase kinase- 3 modulate glycogen metabolism. Chemistry \& Biology 7:793-803

30. Bollen M, Keppens S, Stalmans W (1998) Specific features of glycogen metabolism in liver. Biochem J 336:9-331

31. Latsis T, Andersen B, Agius L (2002) Diverse effects of two allosteric inhibitors on the phosphorylation state of glycogen phosphorylase in hepatocytes. Biochem J 368:309-316

32. Cho H, Mu J, Kim JK, et al (2001) Insulin resistance and a diabetes mellitus-like syndrome in mice lacking the protein kinase Akt2 (PKB beta). Science 292:1728-1731

33. Bae SS, Mu J, Birnbaum MJ (2003) Isoform-specific regulation of insulin-dependent glucose uptake by Akt/protein kinase B. J Biol Chem 278:49530-49536

34. George S, Rochford JJ, Wolfrum C et al (2004) A family with severe insulin resistance and diabetes due to a mutation in AKT2. Science 304:1325-1328

35. Walker KS, Deak M, Paterson A, Hudson K, Cohen P, Alessi DR (1988) Activation of protein kinase B beta and gamma isoforms by insulin in vivo and by 3-phosphoinositide-dependent protein kinase-1 in vitro: comparison with protein kinase $B$ alpha. Biochem J 331:299-308

36. Ono H, Shimano H, Katagiri H et al (2003) Hepatic Akt activation induces marked hypoglycaemia, hepatomegaly, and hypertriglyceridaemia with sterol regulatory element binding protein involvement. Diabetes 52:2905-2913 